\title{
Concomitant pulmonary and central nervous system paracoccidioidomycosis with cerebellar abscess
}

\author{
Lucas Giansante Abud[1],[2], Rodolfo Mendes Queiroz ${ }^{[1]}$ \\ and Thiago Giansante Abud[1],[3]
}

[1]. Documenta, Hospital São Francisco, Ribeirão Preto, São Paulo, Brasil. [2]. Setor de Radiologia, Hospital das Clínicas, Faculdade de Medicina de Ribeirão Preto, Universidade de São Paulo, Ribeirão Preto, São Paulo, Brasil. [3]. Setor de Radiologia, Universidade Federal de São Paulo, São Paulo, São Paulo, Brasil.

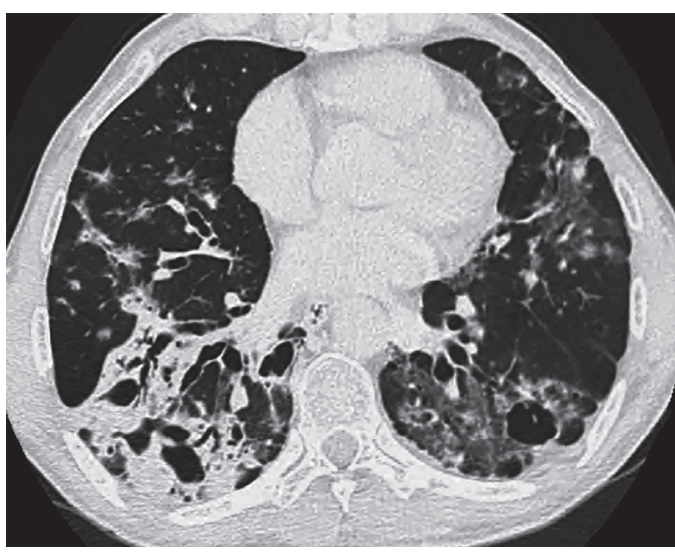

(A)

A 59-year-old man with no previous diagnosis was admitted to hospital with a history of headache, ataxia, and cough.

Computed tomography (CT) of the chest showed groundglass attenuation, consolidation, nodules, cavitations, and fibrotic lesions in both lungs, strongly suggesting the possibility of a granulomatous process (Figure A). These radiological findings are commonly seen in fungal disease, supporting a diagnosis of a chronic form of pulmonary paracoccidioidomycosis ${ }^{(1)}$.

The contrast-enhanced coronal T1-weighted magnetic resonance image (MRI) of the brain showed a ring-enhancing mass in the left cerebellar hemisphere, suggesting a necrotic lesion (Figure B). A hypersignal in the cavity on the axial diffusion-weighted image (Figure C) was interpreted as reduced water molecule movement (restricted diffusion) and reflected a high viscosity of the proteinaceous fluid with a high concentration of inflammatory cells. Although these features are not pathognomonic, they are extremely characteristic of an abscess ${ }^{(2)}$.

The patient underwent surgical drainage of the cerebellar lesion. The histopathological findings were leveduriform structures of Paracoccidioides brasiliensis.

Corresponding author: Dr. Lucas Giansante Abud. Rua Bernardino de Campos 1426, 14015-130 Ribeirão Preto, São Paulo, Brasil.

Phone: 5516 3610-2025

e-mail: abud.lucas@gmail.com

Received 10 August 2015

Accepted 3 September 2015

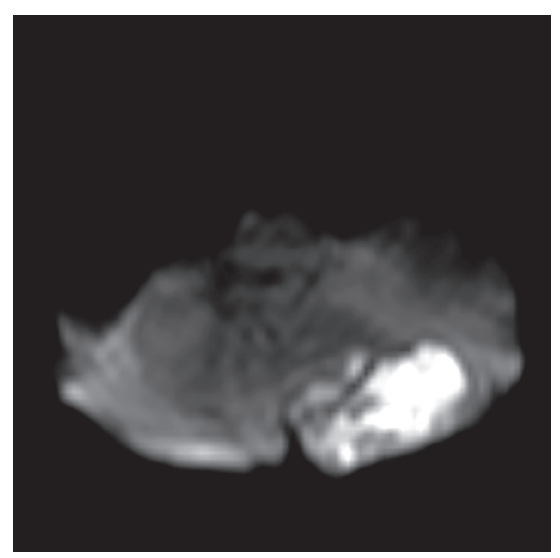

(C)

Paracoccidioidomycosis (PCM) is one of the most common fungal diseases and can compromise one or multiple organs ${ }^{(3)}$. Diagnosis can be confirmed by biopsy, immunological assay, culture, or direct microscopy. Recommended pharmacological treatment includes itraconazole, sulfamethoxazole + trimethoprim, and amphotericin B.

Thus, the combination of chest CT findings, suggesting a granulomatous infectious process, and MRI, showing a probable encephalic abscess, should lead to a diagnosis of PCM with concomitant involvement of the central nervous system and lungs, allowing early initiation of specific treatment and reduction of the associated morbimortality.

\section{REFERENCES}

1. Barreto MM, Marchiori E, Amorim VB, Zanetti G, Takayassu TC, Escuissato DL, et al. Thoracic paracoccidioidomycosis: radiographic and CT findings. Radiographics 2012; 32:71-84.

2. Luthra G, Parihar A, Nath K, Jaiswal S, Prasad KN, Husain N, et al. Comparative evaluation of fungal, tubercular, and pyogenic brain abscesses with conventional and diffusion MR imaging and proton MR spectroscopy. AJNR Am J Neuroradiol 2007; 28:1332-1338.

3. Pedroso VS, Lyon AC, Araújo SA, Veloso JM, Pedroso ER, Teixeira AL. Paracoccidioidomycosis case series with and without central nervous system involvement. Rev Soc Bras Med Trop 2012; 45:586-590. 